\title{
Communicable Diseases: Achievements and Challenges for Public Health
}

\author{
Ursula Schlipköter, ${ }^{1}$ \\ Antoine Flahault ${ }^{2}$
}

\begin{abstract}
The past two centuries have seen enormous achievements in control of infectious diseases, previously the leading cause of death, in large measure due to sanitation and food safety, vaccines, antibiotics and improved nutrition. This has led people to put their faith in the notion that medical science would succeed in overcoming the remaining obstacles. Vaccination has eradicated smallpox, nearly eradicated poliomyelitis and greatly reduced many other highly dangerous infections such as diphtheria, tetanus and measles. New diseases such as HIV and new forms of influenza have taken both professional and popular opinion by surprise and have renewed the challenges before the world public health community. Emergence of antibiotic-resistant strains of common organisms due to overuse of antibiotics and lack of vaccines for many dangerous microorganisms poses problems to humanity. This stresses the need for new vaccines, effective antibiotics and strengthened environmental control measures. New knowledge of the microbiological origins of cancers such as that of the cervix, stomach and liver have strengthened primary prevention and brought hope that new cures will be found for other chronic diseases of infectious origin. Tragically long delays in adopting "new" and cost effective vaccines cause hundreds of thousands of preventable deaths each year in developing and mid-level developed countries. Gains are being made in control of many tropical diseases, but malaria, tuberculosis and other infectious diseases remain enormous global problems. Research and acquisition of new knowledge, risk communication, application of currently available means and fair distribution will be great challenges to public health in the coming decades.
\end{abstract}

Key Words: infectious diseases, Public Health, emerging and re-emerging infections, epidemics, low-income countries

\footnotetext{
${ }^{1}$ Pettenkofer School of Public Health, Institut für Medizinische Informationsverarbeitung, Biometrie und Epidemiologie, Ludwig Maximilian University Munich, Germany.

${ }^{2}$ Dean, Ecole des Hautes Etudes Sante Publique, Paris and Rennes, France.
}

Correspondence: Ursula Schlipköter at email schli@ibe.med.uni-muenchen.de 


\section{INTRODUCTION}

Public health has had enormous triumphs in the field of infectious disease control, ${ }^{1}$ as illustrated by the eradication of smallpox, the near-eradication of poliomyelitis and the eye-opening discovery that stomach ulcer is caused by the Helicobacter pylori organism (see foreword). ${ }^{2}$

The reduced burden of many infectious diseases, such as cholera, typhoid and other enteric infectious diseases which were rampant during the $19^{\text {th }}$ century, can be attributed to sanitation, water and food safety regulations and improved nutrition and living standards. ${ }^{1,3}$ Vaccines developed during the late $19^{\text {th }}$ and throughout the $20^{\text {th }}$ century have successfully taken public health to new heights in terms of improving individual and societal well-being. ${ }^{4}$

In the 1960s, the idea that infectious disease would soon become a thing of the past became widespread in both professional and public circles. In 1963, a respected physician and anthropologist T. Aidan Cockburn, as quoted by Faucci, stated: "We can look forward with confidence to a considerable degree of freedom from infectious diseases at a time not too far in the future. Indeed... it seems reasonable to anticipate that within some measurable time... all the major infections will have disappeared." 5 Five years later, the U.S. Surgeon General noted that "it might be possible with interventions such as antimicrobials and vaccines to close the book on infectious diseases and shift public health resources to chronic diseases." ${ }^{\prime 6,7}$

The dramatic achievement of smallpox eradication was offset by a failure to eradicate malaria, one of the largest killers of children to this day. The campaign led by the World Health Organization (WHO) to eradicate poliomyelitis has made enormous progress, but has still not achieved eradication. Measles has been eliminated as a public health problem in many parts of the world, but despite a great reduction in the rate of measles mortality in developing countries, this disease has continued to kill several hundred thousand children annually during the first decade of the $21^{\text {st }}$ century.

Since the 1980s, a series of unexpected new infectious diseases has emerged, in addition to a resurgence of well known infectious diseases, and emergence of new or resistant variants of previously known pathogens. Over 30 new infectious agents have been detected, presenting tremendous challenges to human health. The ongoing epidemic of the human immunedeficiency virus (HIV) beginning in the 1980s, Creutzfeld-Jakob Disease (CJD) in the 1990s, Severe Acute Respiratory Syndrome (SARS) in the 2000s, drug-resistant tuberculosis (DRTP), Methicillin-resistant Staphylococcus Aureus (MRSA) and malaria resistant to longstanding anti- 
malarial drugs, of which the latter three are on the rise, are but a few examples..$^{8-11}$

At the beginning of the $21^{\text {st }}$ century, a wide variety of animal species, both domesticated and wild, have acted as reservoirs for these pathogens which include viruses, bacteria and parasites. Considering the wide range of animal species involved and the usually complex natural history of the pathogens concerned, effective surveillance, prevention and control of zoonotic diseases pose a real challenge to public health. ${ }^{12-15}$ The newly emerged zoonoses such as bovine spongiform encephalopathy (BSE), other foodborne diseases and a number of viral infectious agents (e.g., Nipah, Ebola, avian H5N1 influenza virus, monkeypox virus) have had serious direct and indirect impacts on public health. ${ }^{16,17}$ As our environment continues to change, more such occurrences can be expected in the future. The hypotheses usually proposed to explain the emergence of these new agents refer to the complex interaction of numerous factors such as relative size of animal species populations, expanding human populations and settlements, change in technology, as well as the probable influence of global climatic changes. ${ }^{18}$

Diseases take a large toll on human life and place a heavy burden on the economy and overall infrastructure of countries. The poorest people of the world continue to be those most affected by infectious diseases. Nearly 2.4 million children continue to die each year from vaccine-preventable diseases. The interaction of poverty and infectious diseases is also related to nutritional deprivations, chronic disease and organization of public health services, all of which are addressed in other articles in this issue. ${ }^{19-22}$ It is therefore imperative that policy makers, public health professionals, infectious disease physicians, and economists act jointly in order to aim for the Millennium Development Goals (MDG), including reducing child mortality and combating HIV/AIDS, malaria and other major diseases..$^{23,24}$

Progress in the field has continued with the development of vaccines against cancer-causing infectious agents, such as hepatitis B and the recent vaccine against human papillomavirus (HPV), the infectious agent associated with cervical cancer. These and other innovations raise the hope of new discoveries and vaccine development against other chronic diseases of infectious origin.

This paper will discuss the challenges and opportunities associated with controlling communicable diseases in the coming decades, within the context of the New Public Health, as it refers to the ways in which health systems manage and monitor threats to population health. 


\section{ACHIEVEMENTS OF THE NINETEENTH AND TWENTIETH CENTURIES}

The current factors that are relevant to the New Public Health in infectious diseases have to be considered within a historical context. During the $19^{\text {th }}$ and $20^{\text {th }}$ centuries, a global transformation in public health was seen with a remarkable decline in mortality rates and a shift of epidemiological patterns from mainly infectious to mainly chronic disease,${ }^{25}$ and the rise of healthy living as a new era of public health. ${ }^{22,24}$

The agricultural and industrial revolutions of the preceding centuries had resulted in socioeconomic changes involving increases in nutrient intake and improvements in sanitation, food safety, water supply, and transportation infrastructures. These factors, along with development of organized public health systems, have been vital in bringing about the decline of infectious disease. ${ }^{4,26}$

Urbanization had initially led to overcrowding in poor housing conditions and resulted in outbreaks of Cholera, tuberculosis, and typhoid fever, to name a few. Implementation of preventive measures was based on the "Miasma theory" according to which poisonous vapor or mist filled with particles from decomposed matter and emissions of organic decomposition from the earth, identifiable by its foul smell, then thought to be the source of most illnesses. This was the basis of the "Sanitary Movement" which addressed sewage disposal, water treatment, food safety programs and public education about hygienic practices, resulting in the decline of the aforementioned diseases. ${ }^{27}$ During the cholera epidemic in London in the 1850s, John Snow traced the origin of and stopped the epidemic by removing the handle of the Broad Street pump, identifying the source of the epidemic to be a contaminated water supply. ${ }^{3}$ Local health boards began to develop and implement water treatment and other sanitary requirements in major cities such as New York in 1866, which subsequently led to implementation of water treatment systems and mandatory pasteurization of milk. ${ }^{28}$ Similarly, in 1892, Max von Pettenkofer, one of the pioneers of public health and advocate of the Miasma theory, prevented an outbreak in Munich by starting treatment of the wastewater system. ${ }^{29,30}$

The "Germ theory", stating that all communicable diseases are caused by microorganisms, was advanced in the mid- $19^{\text {th }}$ century with the classic description of the transmission of measles by Peter Panum in the Faroes Islands in 1846, and gained wide credibility thereafter. ${ }^{31}$ The scientific advances brought about as a result of the germ theory were enormous and over time, took into account biological, as well as sociodemographic and environmental issues. Louis Pasteur developed the scientific and public 
health applications of this theory in his discovery that germs caused spoilage of wine and that prevention of such spoilage could be achieved by a heating process, now known as pasteurization. ${ }^{27}$

The bacteriologic revolution led by Louis Pasteur, Ferdinand Cohn and Robert Koch established the scientific basis of the germ theory and laid the groundwork for the development of the immunological basis for vaccines. Application of new scientific knowledge generated in the late $19^{\text {th }}$ century through Robert Koch's discovery of microorganisms such as Mycobacterium tuberculosis and Vibrio cholerae as the cause of communicable diseases placed the germ theory at the center of scientific advances in infection control. ${ }^{32}$

Discovery and introduction of the sulfa drugs and antibiotics by Selman Waksman, Ernest Duchesne and Alexander Fleming, which resulted in successful treatment of streptococcal and staphylococcal infections, gonorrhoea, syphilis and tuberculosis, represents another milestone within the realm of miracles and successes in the combat against infectious disease. Sulfa drugs, first discovered in 1935 by Gerhard Domagk, were life-saving for soldiers in World War II and are still commonly used today. The discovery and clinical trials of streptomycin in 1944 followed the isolation of the streptomycin producing organism. The discovery that the Helicobacter pylori organism caused stomach ulcer led to successful antibiotic-based therapy for this disease, and the subsequent decrease in stomach cancer rates. ${ }^{33,34}$

Antiviral drugs such as Aciclovir, Interferon or NRTI active against herpes virus, hepatitis B and influenza or AIDS were seen as the dawning of a new era in antiviral therapy. No less important are the therapies which have been developed against fungal and parasitic diseases, and which also contributed greatly to changes in disease patterns and decreasing morbidity and mortality rates. ${ }^{35}$

\section{THE WORLD HEALTH COMMUNITY ACTING TOGETHER}

The immunization against smallpox pioneered by Edward Jenner defined "vaccine preventable diseases" and marked the dawn of numerous universal childhood vaccination programs. Eradication of smallpox was one of the early targets the WHO set after it was founded in 1948. The disease was rampant in the 1950s, when an estimated 50 million cases of smallpox occurred annually, falling to 10-15 million cases by 1967 as vaccination became more universal. In 1967, WHO adopted an intensified plan to eradicate smallpox, which still threatened 60 percent of the world's population, killed every fourth victim, scarred or blinded most survivors, 
and for which there was no treatment. Gradually the disease was isolated to the Horn of Africa and the last case was identified in Somalia in 1977. Global eradication was accepted by the WHO in $1980 .^{36,37}$

Total eradication of a disease requires a specific set of conditions: the human being as the unique host, an antigenetically stable pathogen and an effective vaccine with long-lasting immunity for acute non-chronic diseases which lack animal hosts. ${ }^{38}$ Initially, only smallpox was targeted for eradication, and after this was successfully achieved, other infectious diseases such as poliomyelitis and measles, proving hard to eradicate, were targeted as well as public health problems requiring control and elimination, such as onchocerciasis, leprosy, rubella syndrome and many others. This concept was later adjusted to include stages of control and eradication, not only of infectious diseases but other important health conditions as well, e.g., iodine deficiency disorders (IDD).

\section{Table 1}

Stages of Control or Eradication of Diseases or Conditions Important to Public Health

1. "Control or reduction of disease incidence, prevalence, morbidity or mortality to a locally acceptable level as a result of deliberate efforts; continued intervention measures are required to maintain the reduction. Example: diarrhoeal diseases.

2. Elimination of disease: Reduction to zero of the incidence of a specified disease in a defined geographical area as a result of deliberate efforts; continued intervention measures are required. Example: neonatal tetanus.

3. Elimination of infections: Reduction to zero of the incidence of infection caused by a specific agent in a defined geographical area as a result of deliberate efforts; continued measures to prevent re-establishment of transmission are required. Example: measles, poliomyelitis;

4. Eradication: Permanent reduction to zero of the worldwide incidence of infection caused by a specific agent as a result of deliberate efforts; intervention measures are no longer needed. Example: smallpox; and

5. Extinction: The specific infectious agent no longer exists in nature or in the laboratory. Example: none."

Source: Dowdle WR. The principles of disease elimination and eradication ${ }^{38}$ MMWR Morb Mort Wkly Rep. 1999;48(SU01):23-7. Available from URL: http://www.cdc.gov/mmwr/preview/mmwrhtml/ su48a7.htm. (Accessed 1 June, 2010).

International agencies led by WHO undertook further disease eradication programs, targeting poliomyelitis, neonatal tetanus, and measles, as well as tropical diseases such as leprosy, trachoma, Chagas' disease, drancunculiasis, onchocerciasis, and enteric worms, and succeeded in reversing upward trends in tuberculosis and malaria. ${ }^{39,40}$ 
Vaccines and antibiotics brought a sense of widespread optimism to public health, leading people to believe that all infectious diseases could be conquered, particularly given the extraordinary success of the Salk inactivated polio vaccine and the Sabin attenuated live polio vaccine. ${ }^{41-45}$ Despite great progress in polio control and local elimination due to the international campaign to eradicate polio, this disease remains endemic in four countries (i.e., Nigeria, India, Pakistan and Afghanistan). In Afghanistan, control of this still endemic disease is affected by the war conditions, but the problem more generally concerns the failure of the infrastructure of primary care to raise routine immunization to over 80 percent, and secondly, a failure to adapt policy to special conditions in still endemic areas. Given the current policy options, a combination of inactivated polio vaccine (IPV) and oral polio vaccine (OPV) has the greatest chance to stop circulation of both wild and vaccine associated polio virus derived from antigenic drift of OPV Sabin vaccine virus. The combined policy, which has not received adequate attention from policy makers, should be reconsidered for the transition "end stage" phase of poliomyelitis control and eradication, exploiting the benefits of each vaccine to expand herd and environmental immunity and to protect individuals from either the wild or vaccine derived poliovirus. ${ }^{46}$

Since 1982, WHO and the world public health community have been supported by non-governmental agencies such as the Rotary Club International and GAVI (Global Vaccine Initiative), in an effort to eradicate polio, producing what is one of the largest internationally coordinated public health projects in the world. The GAVI Alliance ${ }^{47}$ - a vaccine-financing partnership including WHO, UNICEF, the World Bank and the Bill \& Melinda Gates Foundation - has also established funds to purchase rotavirus vaccine for poor countries with a high endemic level of rotavirus where vaccine efficacy has been demonstrated. ${ }^{48}$ These types of efforts will save many lives.

The vaccine revolution continued with the measles, mumps, and rubella vaccines in the 1960s, followed in the 1980s by hepatitis B and hepatitis A. Implementation has saved millions of lives, but full coverage using WHO's Expanded Programmme of Immunization would save hundreds of thousands more lives annually. ${ }^{49}$ Haemophilus influenzae type $b$, pneumococcal pneumonia, varicella, and rotavirus vaccines have all been instrumental in preventing human disease and deaths. Another example is the human papillomavirus (HPV) vaccine approved for use in 2006 which prevents infection with the commonest types of human papillomavirus, and associated cervical cancer. However, slow adoption of the newer vaccines leads to 363,000 preventable deaths from Haemophilus influenzae type b, 
254,000 from pertussis, 128,000 from tetanus, 735,000 from pneumococcal pneumonia, 527,000 from rotavirus and some 200,000 from measles. These deaths occur due to failure to implement these now recommended vaccines. ${ }^{50}$ Measles eradication with a global measles vaccine of 82 percent coverage is on the international agenda, but fraught with difficulties linked with reimportation of the disease, even in areas in which measles was thought to have been eliminated. ${ }^{51,52}$

Scientific and technologic advances have modernized public health surveillance and control systems. Detection, diagnosis and monitoring using powerful new tools such as serological tests and various potent molecular techniques are coupled with use of computers and electronic forms of communication to collect, analyze and distribute the surveillance data. These tools provide the statistics representing the burden of disease and mortality which are the foundation for the study of epidemiology and for public health. ${ }^{53,54}$

\section{CHALLENGES TODAY}

Higher standards of living and urbanization, especially in high and middleincome countries, have led to a demographic transition from high to low birth rates and short to long life spans. The burden of illness has shifted from acute childhood infections to chronic non-communicable diseases. ${ }^{22,25}$ Nevertheless, the epidemiologic transition is not complete, unfolding at different rates around the globe. New and emerging infectious diseases have brought important new challenges to public health globally. ${ }^{55}$

Although higher incomes and educational levels, improvements in nutrition, sanitation and sewage management as well as vaccines and medicines have all accounted for the dramatic decline in mortality during the $20^{\text {th }}$ century, huge inequalities persist, and not everyone has been able to enjoy the fruit of public health successes and societal advances. ${ }^{56}$ As a result, some low and middle-income countries have been left behind. The poor health status in these subpopulations can be attributed to problems such as poverty, malnutrition, illiteracy, unsafe drinking water, lack of access to health services, social discrimination, and political conflict.

Leading causes of death ${ }^{57}$ in many developing countries include lower respiratory infections, diarrhoeal diseases, HIV, tuberculosis and malaria (Table 2). The rates of infectious diseases in low-income countries account for much of the global morbidity and mortality (Table 3) due to infectious diseases. ${ }^{58}$ Measles and other infections such as parasitic diseases have to be added to the top ten causes of death for children under five years of age. 
Almost a quarter of global under-five mortality can be attributed to vaccinepreventable disease, so making vaccines available to all can significantly increase child survival rates around the world..$^{59}$

Table 2

The Ten Leading Causes of Death; Low-Income Countries - 2004

\begin{tabular}{l|c|c}
\hline \multicolumn{1}{c|}{ Cause of Death } & Deaths in millions & \% of deaths \\
\hline Lower respiratory infections & 2.94 & 11.2 \\
Coronary heart disease & 2.47 & 9.4 \\
Diarrhoeal diseases & 1.81 & 6.9 \\
HIV/AIDS & 1.51 & 5.7 \\
Stroke and other cerebrovascular diseases & 1.48 & 5.6 \\
Chronic obstructive pulmonary disease & 0.94 & 3.6 \\
Tuberculosis & 0.91 & 3.5 \\
Neonatal infections & 0.90 & 3.4 \\
Malaria & 0.86 & 3.3 \\
Prematurity and low birth weight & 0.84 & 3.2 \\
\hline
\end{tabular}

Source: World Health Organization. The ten leading causes of death by broad income group, 2004. Fact sheet 310, October 2008. ${ }^{57}$ Available from URL: http://www.who.int/mediacentre/factsheets/ fs310/en/index.html (Accessed 2 June, 2010).

Table 3

Global Health Council. Mortality and Morbidity of Infectious Diseases

Mortality and Morbidity Due to Selected Infectious Diseases

\begin{tabular}{l|c|c}
\hline \multicolumn{1}{c|}{ Cause of Death } & Annual Deaths & Annual DALYs* \\
\hline Lower Respiratory Infections & 4.1 million & 94.5 million \\
Diarrhoeal Diseases & 2.1 million & 72.7 million \\
HIV/AIDS & 2 million & 58.5 million \\
Tuberculosis & 1.4 million & 34.2 million \\
Malaria & 889,185 & 33.9 million \\
Measles & 423,710 & 14.8 million \\
Neglected Diseases & 195,098 & 19 million \\
Sexually Transmitted Infections & 128,472 & 10.4 million \\
Polio & 1,195 & 34,399 \\
Other Infectious Diseases & 1.3 million & 28.5 million \\
Emerging Infectious Diseases & N/A & N/A \\
\hline
\end{tabular}

Note: $*$ DALY = Disability-Adjusted Life Years, the years of healthy life lost due to disability, sickness or premature mortality. N/A = not available.

Source: Global Health Council 2009. Mortality and morbidity of infectious diseases. ${ }^{58}$ Available from URL: http://www.globalhealth.org/infectious_diseases/mortality_morbidity/ (Accessed 19 April, 2010). 
Emerging and re-emerging diseases such as the "big three" (HIV/AIDS, malaria and tuberculosis) are accompanied by new problems such as bioterrorism threats, increase of hospital-acquired infections and pandemic outbreaks, to name a few. ${ }^{8}$

Public health is presently being confronted with major challenges, especially in middle-income and low-income countries containing longstanding infectious disease foci ("hotspots") and where problems are perpetuated by political unrest, poverty and lack of adequate health and sanitation infrastructure. For example, pneumonia is the leading cause of child deaths (1.8 million) under the age of 5 worldwide every year. The Global Action Plan for the Prevention and Control of Pneumonia by WHO and UNICEF aims to increase awareness of the disease, to reduce the burden of pneumonia and to provide guidance on how this can be done. ${ }^{60}$

Diarrhoeal diseases are the second leading cause of childhood mortality globally despite the availability of an effective vaccine for rotavirus, the major cause of enteric infections. ${ }^{61,62}$ Unsafe drinking water, lack of sanitation and insufficient use of oral rehydration salts, a simple low cost life saving technology are major contributors to this huge loss of life and to the barriers in reaching the MDGs in many developing countries. ${ }^{63}$

Half of the world's population is at risk of malaria. There are over 250 million cases of malaria each year causing nearly one million deaths, 90 percent of which occur in Africa mainly among preschool-aged children. As chemoprophylaxis has led to resistant plasmodium strains, great efforts have gone into development of new drugs and new production methods based on known protective gene structures. Up until now, mosquito control programs have played the most important role in preventing malarial transmission. ${ }^{64}$ The potential for reducing transmission can be greatly aided by training community health workers to diagnose and manage malaria, promoting widespread use of bed nets, while taking into account cultural issues, such as use of green bed nets instead of white ones which are seen as burial shrouds among many groups.

More than two billion people are infected with the tubercle bacillus (TB) and one in every 10 of those people will become sick with tuberculosis during their lifetime. In 2008, there were 9.4 million new cases and a total of 1.1 million - 1.7 million deaths from TB among HIV-negative people and an additional 0.45 million - 0.62 million among HIV-positive people. A constant supply of quality-assured anti-TB drugs is fundamental to disease control. Directly Observed Treatment, Short-course (DOTS) refers to systematic application of standardised and supervised drug therapy, along with diagnosis by sputum smears. For this purpose, an effective drug 
supply, as well as diagnostic reporting and management systems are essential and serve as the basis of current strategy to achieve this goal. Although DOTS is practiced all over the world, there were an estimated 500,000 new Multidrug-resistant TB (MDR-TB) cases in 2007 with increasing numbers in 2008. Extensively drug-resistant TB (XDR-TB) occurs when resistance to second-line drugs develops. It is extremely difficult to treat, and cases have been confirmed in more than 50 countries. The WHO Stop TB Strategy aims to reach all patients in order to halve prevalence and death by 2015 as compared to $1990.65,66$

Simultaneous infection with both TB and HIV is a lethal combination, each one accelerating the other's progress. TB is the leading killer of people who are HIV-positive. One third of the world's population is still infected with tuberculosis bacilli and the emergence of MDR- and XDR-TB emphasizes the need for TB control and programmatic management. ${ }^{66}$ Effective management involves many parallel and coordinated systems efforts addressing identified cases and high-risk groups, such as HIV patients and IV drug users, with directly observed therapy and social support systems. ${ }^{67}$

Data from the AIDS Epidemic Update 2009 show that with 33.4 million infected globally, more people are living with HIV than ever before. This increase can be attributed to both population growth and longer life expectancy thanks to wider availability and the beneficial effects of antiretroviral therapy, due to which approximately 12 million life-years have been saved between 1996 and 2008. New HIV infections have been reduced by 17 percent since the year 2000 and almost all countries show a downward trend in infection rates. Increased prevalence due to new infections is reported from Eastern Europe, Central Asia and other parts of Asia. Nevertheless, in 2008, sub-Saharan Africa accounted for 71 percent of all new infections. It is well documented that serodiscordant couples are the root of new infections in some parts of Africa. In high and middleincome countries, injection drug users, men who have sex with men and prisoners, among others, are still at high risk of HIV infection. ${ }^{68}$

Tropical diseases include those diseases which are associated with poverty and unsanitary conditions in poor and developing countries usually located in tropical regions. Despite great progress in leprosy, filariasis and onchocerciasis control, approximately one billion people are affected by neglected tropical diseases (NTD). This group of disease includes: Buruli ulcer, Chagas disease, cholera/epidemic diarrhoeal diseases, dengue/dengue hemorrhagic fever, dracunculiasis (guinea-worm), endemic treponematosis (yaws, pinta, endemic syphilis), human African trypanosomiasis (sleeping 
sickness), leishmaniasis, leprosy, lymphatic filariasis, onchocerciasis, schistosomiasis, helminth infections (roundworm, hookworm and whipworm), and trachoma. Most are of parasitic character and thrive in tropical climates. Once widely dispersed, these diseases are now concentrated in settings of extreme poverty, such as urban slums, conflict zones, or other conditions associated with poverty which allow a given infectious agent to thrive. ${ }^{41,69}$

Co-infection with certain tropical diseases and HIV is even more worrisome and often proves lethal. As an example, Sudan and Ethiopia are currently facing a surge in leishmania/HIV co-infection. WHO reports that HIV infection increases the risk of developing visceral leishmaniasis by a factor of 100-1000 in endemic areas. All co-infected patients eventually die from other opportunistic infections, but without antiretroviral drugs, as is the case in many impoverished areas, they die within two years of contracting leishmaniasis. ${ }^{70} \mathrm{WHO}$ has developed a comprehensive framework within its Global Network for Neglected Tropical Diseases, recommending preventive chemotherapy and methods to make it available to those most in need. This framework is an important model for disease control and poverty reduction, helping to promote equity and ethics in developing countries and offer humanitarian assistance. These could all be incorporated into a larger foreign policy framework to facilitate control of NTDs, strengthen local health systems with community involvement and facilitate monitoring and accountability. ${ }^{71}$

Sexually transmitted diseases (STDs), which WHO is aiming to control primarily though education among young people, remain one of the top five reasons that adults in developing countries seek medical care. Yet these numbers contain a significant underreporting bias, as the global effort for emerging infectious disease surveillance and research is poorly organised, and resources for efficient surveillance systems are badly needed in lowincome countries. ${ }^{72}$

The recent H1N1 influenza pandemic once again brought the sphere of infectious disease into the public eye and has raised public awareness and controversy regarding large-scale public health measures. Although the WHO plays a key role in the diffusion of global alert messages, international coordination, distribution of guidelines and recommendations, and global monitoring of the pandemic, each country is left to cope with the health threat, as it presents itself in that locality, and to devise strategic plans within the confines of its own health system. However, allocation of resources and access to health services often seem to be reserved for the industrialized countries with a trained public health workforce of relatively 
large size and a strong support system including everything from wellequipped laboratories to immunization capacity ${ }^{73}$ Pneumonia and influenza are common causes of death, eighth in the US and seventh in Canada. In the US, in 2005, more than 60,000 deaths occurred among persons age 15 years and over. Between 1998 and 2005, the US rate for hospitalizations due to infections increased from 1525 to 1667 per 100,000 persons. Between 10 and 20 percent of hospitalizations for pneumonia cases were admitted to intensive care units, where the mean savings for a half day reduction in hospitalization is calculated to be US $\$ 1.7$ billion annually. ${ }^{74}$

\section{CHALLENGES OF HIGH-INCOME COUNTRIES}

Evolution of new microorganisms and the consequential rise of resistant microbial agents have often been the consequence of inappropriate use or overuse of antibiotics. For example, MDR- and XDR-TB developed as a response to insufficient TB control methods and failures of standard treatment. ${ }^{75}$ Outbreaks of Methicillin-resistant Staphylococcus Aureus (MRSA) and other healthcare-associated infections (HCI) threaten numerous settings in developed countries.

Coordinated efforts to monitor and prevent misuse of antibiotics are crucial to reducing the spread of microbial resistance, which can arise due to factors such as self-medication, prescription of antibiotics for viral infection and general overuse of antibiotics. Fortunately, EU member states have put measures in place to monitor antibiotic use in order to prevent resistance. ${ }^{76}$ The majority of EU countries coordinate actions to improve prescribing practices, implementing nationally accepted guidelines on appropriate use of antimicrobials for surgical prophylaxis and common human infections, as well as educational campaigns to raise awareness on antimicrobial resistance. ${ }^{77}$

The economic burden of communicable diseases and their complications including that in developed countries is high, as it is a leading cause of hospitalization. MRSA and hospital-acquired pneumonias are a growing problem in hospitals worldwide. ${ }^{78}$ The US Centers for Disease Control (CDC) estimate that of "36 million people admitted to US hospitals every year, nearly two million patients acquire an infection annually during treatment, and over 80,000 patients die from complications resulting from the infection." "Up to one-third of infections acquired in healthcare settings are preventable." ${ }^{, 9}$ Furthermore, the CDC estimates that if nosocomial bloodstream infections alone were counted, they would represent one of the top thirteen causes of death in the US. Thus, effective infection control 
programs including outbreak investigations and promotion of sanitary practices as well as access to improved infection-control technology such as antibiotic-bonded vascular catheters and alcohol hand-cleansing materials are essential in hospitals and in the community. ${ }^{80-82}$

The failure so far to eradicate polio, as illustrated by new cases in Tadzhikistan, signify recurrence in a WHO Euro-Region, a prime example of a situation where political conditions have been a factor in hindering public health efforts. A report entitled, "Independent Evaluation of Major Barriers to Interrupting Poliovirus Transmission" has been completed, in response to a request in January 2009 from the Executive Board of WHO, prompted by delays in attaining global polio eradication. The recommendations and subsequent strategic decisions made by the advisory bodies will form the foundation for an urgent, three-year 2010-2012 Programme of Work to Interrupt Wild Poliovirus Transmission Globally. ${ }^{46,83}$

Wars and natural disasters also create environments where pathogens can thrive. New threats of bioterrorism, such as the anthrax assaults of 2001, are a consequence of the changing political and social environments that challenge organized public health systems. Recent transformations of the environment due to climate change have led to flooding and changes in temperature, which resulted in the migration of disease vectors to higher latitudes and ultimately brought about the 2007 Chikungunya outbreak in Italy, to give but one example. ${ }^{84-89}$ Other diseases such as malaria, Dengue Fever, cholera, and food-borne infections are also sensitive to climate and are thus of particular concern.

Host genetic factors play a major role in determining differential susceptibility to major infectious diseases of humans, such as malaria, HIV/AIDS, tuberculosis, hepatitis B and invasive pneumococcal disease. Infectious diseases such as influenza, Dengue, West Nile virus and Chikungunya, which are of relatively benign character in the majority of cases, can take on a severe form in immunocompromised people and those with chronic diseases. The great majority of susceptibility loci and the complex pathogenesis such as the interaction between pathogens and the immune system remain to be identified. ${ }^{90,91}$ Furthermore, there are studies on genetic factors and chronic infections fostering the development of cardiovascular diseases and several types of cancer. Patients with iatrogenic or disease related immune suppression are highly susceptible to infection and are thus, at increased risk for cytomegalovirus, human herpes virus, hepatitis $\mathrm{B}$ and $\mathrm{C}$, and fungal infections. In this context, population growth of the elderly leading to a significant demographic transition has to be considered. Risk of pneumococcal infection and seasonal influenza - both 
vaccine preventable diseases - due to immunosenescence in this age group has become an issue especially in high-income countries. Although tetanus infections have diminished dramatically since the tetanus toxoid vaccine was introduced, the disease has not disappeared. In 2005 there were 25 tetanus cases in the United States and 147 cases in Europe, mainly in elderly patients. ${ }^{92}$

Another challenge related to peoples' behaviour is illustrated by the persistence of measles in Europe. Successful prevention in the past decades has undermined the reason for its own existence. Suboptimum vaccination coverage is a result of a variety of obstacles in several countries such as perceived vaccine DPT and MMR scares in the United Kingdom in the 1980s and 1990s respectively, anthroposophic or religious objectors in Germany and the Netherlands or political unrest in the Balkans. Additionally, rich countries must be aware of Rose's prevention paradox, the population approach to maximizing herd immunity that seems to be a great effort for the benefit of a mere few. High-income country have to accept responsibility for countries with poor health systems, avoiding reimportation of measles from countries with low rates of population coverage as well as from risk groups which shun immunization for religious or other reasons. ${ }^{93}$,

In 2001, an estimated global total of over 23 million disability-adjusted life years was lost due to measles. ${ }^{94-96}$ The availability of an inexpensive and highly effective vaccine makes measles immunization one of the most costeffective public health interventions. Measles vaccination coverage has improved, but to variable degrees in different regions. First-dose measles vaccination coverage has increased from 72 percent to 83 percent worldwide, with the estimated number of measles deaths falling by 78 percent from an estimated 733,000 deaths in 2000 to 164,000 in 2008. Vaccination played a crucial role; however, an estimated 24 million children, who are most at risk, have not been reached (Figure 1).

In the Eastern Mediterranean region, the number of measles deaths fell by 93 percent between 2000 and 2008, an accomplishment resulting from intensified vaccination campaigns which attained the United Nations' goal of reducing measles deaths by 90 percent by 2010 three years early (2007). In the African region, measles deaths decreased by an estimated 92 percent between 2000 and 2008. The risk of resurgence of disease in Africa is great, reinforcing the importance of timely campaigns and stronger immunization services. The progress in Southeast Asia has been limited. With a 46 percent decline in measles deaths, hundreds of children are still being infected by this disease every day. In 2008, an estimated three out of four measles deaths occurred in India. The goal of reducing measles deaths worldwide 
by 90 percent is dependent on the Indian government taking action. The Ministry of Health has shared plans for campaigns in 2010, and the Measles Initiative has offered both technical and financial support. The numbers of unimmunized children in low-income and middle-income countries, approximately 2 million in Nigeria, 7.6 million in India, 1.1 million in China, 0.8 million in the Congo and 0.74 million in Ethiopia, still pose an enormous challenge to public health. ${ }^{97}$

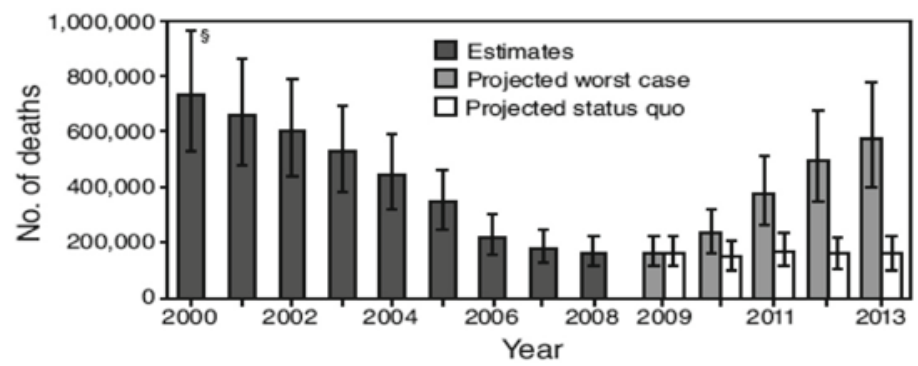

Fig. 1. Estimated Number of Measles Deaths Worldwide, 2000--2008, and worst case/status quo projections of possible resurgence in measles mortality, 2009-2013.

Note: Source: $\S-95 \%$ uncertainty intervals.

Source: Centers for Disease Control. Global measles mortality, 2000-2008. Morb Mort Wkly Rep. 2009; 58;1321-6. Available at URL: http://www.cdc.gov/mmwr/preview/mmwrhtml/mm5847a2. htm (Accessed 14 May 2010). ${ }^{51}$

Some of the changes seen in the $20^{\text {th }}$ century became the problems of the $21^{\text {st }}$; these challenges include, but are not limited to mass travel and rapid transportation, urbanization, and a growing and ageing population, including a high proportion of chronically ill and immunosuppressed. Increasing prevalence of Chlamydia infections and STDs in Europe reflects widespread changes in risk behaviour among the general adult population. ${ }^{62}$ Finally, rapid transportation of crowds of people all over the globe has helped facilitate the spread of the new H1N1 influenza virus, leading to the first pandemic of the $21^{\text {st }}$ century.

\section{THE FUTURE: OPTIMISM AND ADVOCACY, BUT NOT COMPLACENCY}

The most recent H1N1 outbreak, which took the world by storm in May of 2009 and was still raging at the end of 2009 in many parts of the planet, showed that in this day and age, even with the advancement of science, the 
potential for a pandemic is still present. The latest pandemic brought to light the importance of two key elements, both of which are indispensable to the effective combat against infectious disease on a global scale. Firstly, a reasonably good understanding of the mechanisms underlying viral transmission and contagion is imperative. Secondly, and perhaps more importantly, the public's adherence to control and preventive measures is of the utmost importance. Though these two elements should ideally go hand in hand, they are not always both present at the same time.

A population's perception of risk is essential when seeking compliance with a given protective measure. One of the most surprising observations made during the recent pandemic was that in numerous countries, only a small minority of the population was willing to get vaccinated. Vaccine manufacturers and scientists acted very quickly and mobilised all available forces to produce an effective vaccine in record time (less than six months), only to make it available to a public that proved to be very hesitant or even afraid to be vaccinated. This demonstrates that having the capacity to quickly deliver a vaccine in large amounts, in and of itself, does not suffice in the effort to control an infectious disease. The reason for low vaccination levels was certainly not due to a lack of information, because in no previous point in history had there been so much discussion about an ongoing pandemic in the media. ${ }^{98}$ However, risk communication measures were not effective, especially in regions with high levels of healthcare. Lack of coordinated information via public media created confusion and uncertainty. ${ }^{99}$ This phenomenon underlines the great need to associate humanities-based research, in particular that concerning perception of risk, with that in the basic sciences. Moreover, international comparisons need to be conducted with regards to these issues.

The H1N1 influenza pandemic also exposed the high level of imprecision inherent in health surveillance systems the world over. The United States is widely considered to maintain one of the best surveillance systems in the world. Nevertheless, during the course of the pandemic, the figures representing the mortality and morbidity associated with H1N1 virus had to be multiplied fourfold to portray the situation more accurately. ${ }^{100}$ Very few countries went to the extra effort of conducting sero-prevalence studies, and prior to the peak of the epidemic, not a single country had released reliable figures concerning the number of people infected.

Additionally, even the most reliable estimates of influenza come from volunteer-based networks of general practitioners who merely identify flulike illness without formal confirmation of viral presence. Therefore, whether a given case is influenza-based frequently remains unknown. 
Microbiological samples come most often from hospitalized cases who reflect but a small proportion of the infected population. The same holds true for other infectious diseases such as malaria, dengue, and viral hepatitis, to name a few. The degree of uncertainty is huge; for example, we do not know precisely if the number of those who die each year due to malaria is closer to 1 million or 3 million. ${ }^{54}$

While developed countries manage to contain epidemics despite the shortcomings of the surveillance systems by mounting efforts of great magnitude, one can imagine that the issue of emerging infectious diseases takes on an even more dismal character in developing countries where health surveillance may be virtually nonexistent and the health system does not have the means to meet the considerable needs of the population during an outbreak. If 10-20 percent of patients hospitalized in intensive care units in developed countries due to H1N1 influenza end up dying, it can be surmised that these proportions would be higher in places where the sanitary infrastructure is lacking and intensive care units are either very few or nonexistent.

WHO, the European Union and the European Centre for Disease Control (ECDC) currently do not have a common recommended immunization schedule. This lack of a cross-national immunization programme has, for instance, prevented former socialist countries from updating their immunization schedules and from catching up with the content of modern immunization guidelines, leading to the spread of preventable disease across the region. The UK National Health Service has an advanced immunization program for children, including hepatitis B vaccine for newborns of women who are sero-negative, but not including rotavirus or varicella vaccines, while many developed countries use these vaccines on all children. Many European countries are well behind known and current "best practices" applied in Europe and those of the CDC in the US. The European Union and its health organizations should adopt a harmonized recommended guideline for child and adult immunization programmes. ${ }^{101-103}$

The WHO Strategic Advisory Group of Experts (SAGE) on immunization has, however, in recent years taken on a much stronger professional and advocacy role in vaccine matters. The leadership of international organisations is essential in promoting immunization coverage by strengthening primary care infrastructures and adoption of the expanding roster of highly effective vaccines available. The same applies to guidelines for managing nosocomial infections and antibiotic resistance. Leadership is needed to make politicians, and in particular, Ministries of Finance, eager to provide resources to enlarge the scope of immunization, which is 
clearly among the most effective of all public health programs. It is obvious that lack of concerted coordination between countries in the realm of communicable diseases will hinder international work on disease control and eradication. Common guidelines for national immunization programs will be essential in eradicating diseases such as measles, among many others.

\section{CONCLUSION}

Mortality due to infectious disease has fallen dramatically in the past centuries as a result of sanitary and food safety development along with vaccines, antibiotics and other advances in societal conditions and medical sciences. However, the challenges of population growth, urbanization, deforestation, pollution, global climate change and global movement of populations have been associated with a shift in geographical distribution and accelerated diffusion of old and new pathogens resulting in an increased number of outbreaks. ${ }^{104}$

The health, social, economic, and political consequences associated with these emerging diseases are still significant to public health. In the context of the New Public Health, they are still central issues because of the enormous unfulfilled potential to reduce morbidity and mortality globally. The public health community has learned much about facing new challenges of newly emerging or as yet widespread infectious diseases, as well as about infections as causes of chronic diseases.

Epidemics often have unforeseen consequences. The SARS episode of 2003 not only forced numerous airline companies to go bankrupt, but also disrupted commerce with Southeast Asia over the course of several weeks. Chikungunya had important repercussions on tourism in the Indian Ocean in 2006. Similarly, the reappearance of measles and mumps as epidemic and endemic diseases in countries particularly in Western Europe, including Britain, France, Germany, Italy and Switzerland, points to the resurfacing of preventable infectious diseases and the importance of maintaining up-todate immunization practices with high coverage. ${ }^{105}$

Infectious diseases are a significant cause of hospitalization, especially among vulnerable population groups, such as those with chronic disease and the elderly, placing a severe economic burden on health insurance and national health services. This means that greater attention must be paid to immunizing these subgroups especially for influenza and pneumococcal pneumonia, given that the pneumococcal vaccine has been associated with a 39 percent reduction in hospital admissions due to pneumonia from any 
cause. The success of booster vaccination in the elderly depends on previous exposure to influenza, the vaccine types applied earlier in life as well as on pre-vaccination antibody titers. ${ }^{106-111}$

Global anticipation of the most recent influenza epidemic has required international, national and local health authorities to undertake extensive preparation. Despite the preparation, public awareness and acceptance of immunization were insufficient and the pandemic eventually faded from public view by itself. Hence, much effort is still needed to better understand the biological mechanisms of viral transmission and diffusion as well as people's behaviours/attitudes in the face of risk before we can hope to better combat tomorrow's outbreaks.

The future will undoubtedly bring scientific advances to mankind as discoveries of new microbiological agents of important infectious diseases and those causing chronic diseases arise. Some new discoveries will render diseases preventable and treatable, as in the cases of vaccines for hepatitis $\mathrm{A}$ and $\mathrm{B}$, treatment for stomach ulcer caused by Helicobacter pylori and the vaccine for human papillomavirus, the cause of cervical cancer. New vaccine production methods will reduce the costs of vaccines, making them more affordable to developing countries. New knowledge concerning micronutrients, oral diseases and infectious diseases will become part of public health methodology. New methods of producing vaccines against infectious agents will bring huge public health gains in the coming decades, but the urgency is great for new vaccines, such as that for malaria, hepatitis $\mathrm{C}$, and dengue.

The lessons of emerging diseases need to be carefully studied, as potentially lethal infectious agents, such as Ebola, Lassa fever and Marburg disease viruses may undergo genetic shift and modify their lethal characteristics. Carriers may then survive to transmit the virus beyond their local origins, as in the case of SARS and H1N1 influenza. ${ }^{12-114}$ Infections are unequally spread and unpredictably transferred around the world. Rapid mass transportation and human mobility helps introduce and spread organisms to previously unexposed populations, which can then become resistant to treatments available, thus rendering the disease even more dangerous. ${ }^{115,116}$

Technological advancement in antimicrobial drugs will have great influence on the future control of infectious diseases, but low technology also has much to contribute. Oral rehydration solutions are life-saving for children with diarrhoeal disease and poor nutrition status. ${ }^{117}$ Fairly inexpensive basic sanitation and water treatment techniques and oral rehydration solutions can save hundreds of thousands of lives that would 
otherwise be lost to cholera and other waterborne diseases. ${ }^{53}$ Bed nets, environmental control of standing water where mosquito breeding occurs, and involvement of community health workers (such as case finders) can play a crucial role in prevention of malaria transmission in endemic areas. ${ }^{118,119}$ Male circumcision is an effective preventive measure to reduce susceptibility to HIV and STI transmission, and is being widely adopted in many African countries. ${ }^{120,121}$

There is good reason for cautious optimism given all the progress which has been made in recent years on account of the tremendous efforts in public health. Since 2005, coverage of antiviral treatment in poorer countries has increased tenfold, "resulting in the first decline in the number of AIDS deaths since the epidemic was recognized in the 1980s." 122 In December of 2008, 4 million people in developing regions had access to antiviral drugs; this represents a 50 percent increase since December of $2006 .{ }^{105}$ Many more people with HIV are now able to receive treatment than before, especially children. Nevertheless, for every person who began an antiretroviral course in 2007, three new people were infected with HIV, and over 60 percent of those who needed treatment were not able to access it. ${ }^{123}$

The State of the World's Vaccines and Immunization report of 2009 pointed out that more infants have been immunized than ever before. ${ }^{91}$ The Bill and Melinda Gates Foundation as part of the GAVI Alliance donated another US $\$ 10$ billion over the period from 2010 to 2020 to promote research and development as well as delivery of vaccines to the world's poorest countries. However, government and the private sector must support developing countries to reduce child mortality by the end of the decade. ${ }^{124}$

Optimism but not complacency is justified. Political and financial support is needed to maintain and develop the gains achieved in the past century and to transmit the latest knowledge and technology to many parts of the world where preventable deaths measure in the hundreds of thousands. The potential for saving human life is high with current technology. The New Public Health calls for fair distribution of resources and the timely application of existing knowledge and tools; this mainly rests on political will, funding, initiative and training.

\section{Acknowledgements}

We particularly thank our colleagues, Ted Tulchinsky, Joan Bickford, and Ilana Levin, for their excellent contributions and gratefully acknowledge their sedulous assistance.

Conflicts of interest: None declared. 


\section{REFERENCES}

1. Centers for Disease Control. Achievements in public health, 1900-1999: control of infectious diseases. MMWR Morb Mortal Wkly Rep. 1999;48:621-9.

2. Flahault A, Tulchinsky TH. Preface: From science to public health: the Helicobacter pylori case. Public Health Reviews 2010;32:7-9.

3. Snow J. Snow on Cholera: A Reprint of Two Papers. New York: Commonwealth Fund, 1936.

4. Centers for Disease Control. Achievements in public health, 1900-1999 impact of vaccines universally recommended for children - United States, 1900-1998. MMWR Morb Mortal Wkly Rep. 1999;48:243-8.

5. Cockburn A. The evolution and eradication of infectious diseases. Westport (CT): Greenwood Press: 1964. (reprint 1983).

6. Fauci AS. Emerging and re-emerging infectious diseases: the perpetual challenge. 2005. Robert H. Ebert Memorial Lecture. New York: Milbank Memorial Fund and the Association of American Medical Colleges (AAMC): 2006. Available from URL: http://www.milbank.org/reports/0601fauci/0601fauci. html (Accessed 17 March, 2010).

7. Sassetti CM, Rubin EJ. The open book of infectious diseases. Nature Medicine. 2007;23:279-80.

8. The Global Fund To Fight Aids, Tuberculosis and Malaria. The global fund 2010: innovation and impact. Geneva: Global Fund; 2010. Available from URL: http://www.theglobalfund.org/documents/replenishment/2010/Global Fund_2010_Innovation_and_Impact_en.pdf (Accessed 14 March, 2010).

9. The National Advisory Committee on SARS and Public Health. Learning from SARS: renewal of public health in Canada. Ottawa: Government of Canada; 2003. Available from URL: http://www.phac-aspc.gc.ca/publicat/sars-sras/pdf/ sars-e.pdf (Accessed 17 April, 2010).

10. National Institute of Neurological Disorders and Stroke. Creuzfeldt-Jakob disease fact sheet. Available from URL: http://www.ninds.nih.gov/disorders/cjd/detail_ cjd.htm (Accessed 17 April, 2010).

11. Public HealthAgency of Canada. Fact sheet-Methicillin-resistant Staphylococcus aureus. Available from URL: http://www.phac-aspc.gc.ca/id-mi/mrsa-eng. php (Accessed 17 April, 2010).

12. World Health Organization. Vector control of malaria. Available from URL: http:// www.who.int/malaria/vector_control/ivm/en/index.html (Accessed 17 April, 2010).

13. World Health Organization. Clean care is safer care. Available from URL: http:// www.who.int/gpsc/en/ (Accessed 18 March, 2010).

14. Cutler SJ, Fooks AR, van der Poel WH. Public health threat of new, reemerging, and neglected zoonoses in the industrialized world. Emerg Infect Dis. 2010; 16:1-7.

15. Blancou J, Chomel BB, Belotto A, Meslin FX. Emerging or reemerging bacterial zoonoses: factors of emergence, surveillance and control. Vet Res. 2005;36: 507-22. 
16. World Health Organization. Ebola haemorrhagic fever, fact sheet No. 103, December, 2008. Available from URL: http://www.who.int/mediacentre/ factsheets/fs103/en/ (Accessed 13 April, 2010).

17. World Health Organization. Protection of individuals with high poultry contact in areas affected by avian influenza $\mathrm{H} 5 \mathrm{~N} 1$ : consolidation of pre-existing guidance, February, 2008. Available from URL: http://www.who.int/csr/ disease/avian_influenza/guidelines/high_contact_protection/en/index.html (Accessed 17 April, 2010).

18. UN Millennium Project Task Force on Environmental Sustainability. Environment and human well being: practical strategy. New York: United Nations Development Programme; 2005. Available from URL: http://www.unmillenniumprject. org/documents/nvironSust_summary.pdf (Accessed 14 March, 2010).

19. Tulchinsky TH, Micronutrient deficiency conditions: global health issues. Public Health Reviews 2010;32:243-255.

20. Halpin HA, Morales MM, Martin-Moreno JM. Chronic disease prevention and the new public health. Public Health Reviews 2010;32:120-154.

21. Harrison GG. Public health interventions to combat micronutrient deficiencies, Public Health Reviews 2010;32:256-266.

22. Fielding JE, Teutsch S, Breslow LA. A framework for public health in the United States. Public Health Reviews 2010;32:174-189.

23. United Nations. Millennium Development Goals Report, 2008. New York: United Nations; 2009.Available fromURL: http://mdgs.un.org/unsd/mdg?Resources/ Static?Products/Progress2008/MDG_Report_2008_En.pdf\#page=22 (Accessed 8 April, 2010).

24. United Nations. MDG 4: Reduce child mortality. Fact sheet: tetanus a silent killer of maternal and neonatal mortality. Available from URL: http://www. un.org/millenniumgoals/2008highlevel/pdf/newsroom/Goal\%204\%20FINAL. pdf (Accessed 14 March, 2010).

25. Tulchinsky TH, Varavikova EA. What is the "new public health"? Public Health Reviews 2010;32:25-53.

26. Centers for Communicable Disease Control and Prevention. Achievements in public health, 1900-1999: changes in the public health system. MMWR. Morb Mortal Wkly Rep. 1999;48:1141-7.

27. Rosen, G. 1958. A History of Public Health. New York: MD Publications. Republished as Expanded Edition. Baltimore, MD: Johns Hopkins University Press, 1993.

28. Centers for Disease Control. Achievements in public health 1900-1999: safer and healthier foods. MMWR Morb Mortal Wkly Rep. 1999;48:905-13.

29. Locher WG. Von Pettenkofer M (1818-1901) as a pioneer of modern hygiene and preventive medicine. Env Health Pre Med. 2007;12:238-45.

30. Oppenheimer GM, Ezra Susser E. Invited commentary: the context and challenge of von Pettenkofer's contributions to epidemiology. Am J Epidemiol, 2007 166:1239-1241. 
31. Panum PL. Observationsmade during the epidemic of measles in the Faroe Islands in the year 1846 (a translation from the Danish). (Book review) Emerson H. Am J. Public Health. 1940;30:1245-6.

32. History of the germ theory. BMJ. 1888;1:312.

33. Encyclopedia Britannica. First sulfa drug. Available from URL: http://www. britannica.com/EBchecked/topic/168420/Gerhard-Domagk (Accessed 18 March, 2010).

34. Waksman SA. Streptomycin: background, isolation, properties and utilization. Nobel Lecture, December 12, 1952. Available from URL: http://nobelprize. org/nobel_prizes/medicine/laureates/1952/waksman-lecture.pdf (Accessed 18 March, 2010).

35. Berger TG, Greene I. Bacterial, viral, fungal and parasitic infections in HIV disease and AIDS. Dermatol Clin. 1991;9:465-92.

36. Henderson DA. The history of smallpox eradication: Professor Donald Henderson podcast. Available from URL: http://www.ucl.ac.uk/histmed/ audio/smallpox/henderson_podcast (Accessed 18 March, 2010).

37. World Health Organization: Smallpox 2009. Available from URL: http://www. who.int/mediacentre/factsheets/smallpox/en/ (Accessed 18 March, 2010).

38. Dowdle WR. The principles of disease elimination and eradication. MMWR Morb Mort Wkly Rep. 1999;48 (SU01);23-27. (Accessed 1 June, 2010).

39. Arita I, Wickett J, Nakane M. Eradication of infectious diseases: its concept then and now. Jpn J Inf Dis. 2004;57:1-6. Available from URL: http://www. nih.go.jp/JJID/57/1.pdf (Accessed 14 March, 2010).

40. Department of Control of Neglected Tropical Diseases. Neglected tropical diseases, hidden successes, emerging opportunities. Geneva: World Health Organization; 2006. Available from URL: http://whqlibdoc.who.int/hq/2006/ WHO_CDS_NTD_2006.2_eng.pdf (Accessed 14 March, 2010).

41. Tulchinsky TH. Polio eradication - end stage challenges. Bull World Health Organ. 2005;83:160.

42. John TJ. A developing country perspective on vaccine - associated paralytic poliomyelitis. Bull World Health Organ. 2004;82:53-8.

43. Thomson KM, Radboud J. Tebbeus D, Pallansch MA, Kew OM, Sutter RW, et al. The risks, costs, and benefits of possible future global policies for managing polio viruses. Am J. Public Health. 2008;98:1322-30.

44. World Health Organization. Resurgence of wild polio virus types 1 and 3 in 15 African countries, January 2008 - March 2009. Wkly Epidemiol Rec. 2009; 84:133-40.

45. Centers for disease Control. Update on vaccine-derived polio viruses Worldwide, January 2008 - June 2009. MMWR Morb Mort Wkly Rep. 2009; 58(36):w002-6.

46. Centers for disease Control. Progress toward interruption of wild poliovirus transmission - worldwide, 2009. MMWR Morb Mort Wkly Rep. 2010;59: 545-50. 
47. Global Alliance for Vaccine Initiatives. GAVI partners' forum, Hanoi, Vietnam, November 18-20, 2009. Summary report. Available from URL: http://www. gavialliance.org/resources/2009_GAVI_Partners_Forum_Summary_Report. pdf (Accessed 19 April, 2010).

48. Parashar UD, Glass RJ. Rotavirus vaccines - early success, remaining challenges. N Engl J Med. 2009;360:1063-65.

49. World Health Organization. Challenges in global immunization and the global immunization vision and strategy 2006-2015. WER Wkly Epidemiol Rec. 2006;81:189-96.

50. World Health Organization. Global immunization data, October, 2009. Available from URL: http://www.who.int/immunization/newsroom/GID_english.pdf (Accessed April 19, 2010).

51. Centers for Disease Control. Global measles mortality, 2000 - 2008. MMWR Morb Mort Wkly Rep. 2009;58:1321-6.

52. WHO/UNICEF. Joint annual measles report 2008: strengthening immunization through measles control, Phase IX. Revised final 2009.Available from URL: http://www.measlesinitiative.org/mi-files/Reports/Measles\%20Initiative/ Annual\%20Reports/REVISED\%20FINAL\%20Measles\%20AR\%202008. pdf (Accessed 19 April, 2010).

53. Guglielmetti P, Coulombier D, Thinus G, Van Loock F, Schreck S. The early warning and response system for communicable diseases in the EU: an overview from 1999 to 2005, Euro Surveill. 2006;11:215-20.

54. Semenza JC, Giesecke J. Intervening to reduce inequalities in infections in Europe. Am J Pub Health. 2008;98:787-92.

55. Fauci AS, Touchette NA, Folkers GK. Emerging Infectious Diseases: a 10-Year Perspective From the National Institute of Allergy and Infectious Diseases. Emerg infect Dis. 2005;11:519-25.

56. Semenza JC, Giesecke J. Intervening to reduce inequalities in infections in Europe. Am J Pub Health. 2008;98:787-92.

57. World Health Organization. Fact sheet - The top ten causes of death . Fact sheet No 310, October, 2008. Available from URL: http://www.who.int/mediacentre/ factsheets/fs310_2008.pdf (Accessed 19, April, 2010).

58. Global Health Council. Mortality and morbidity of infectious diseases, 2009. Available from URL: http://www.globalhealth.org/infectioudiseases/moratality_ morbidity/ (Accessed 19 April, 2010).

59. Dabbagh A, Eggers R, Cochi S, Dietz V, Strebel P, CherianT. A new global framework for immunization monitoring and surveillance. Bull World Health Organ. 2007;85:904-5.

60. World Health Organization, UNICEF: Global action plan for prevention and control of pneumonia (GAPP). Geneva/New York: World Health Organization, UNICEF; 2009. Available from URL: http://whqlibdoc.who.int/hq/2009/ WHO_FCH_CAH_NCH_09.04_eng.pdf (Accessed 14 March, 2010).

61. United Nations. Millennium Development Goals: goal 7 - ensure environmental sustainability. Available from URL: http://www.undp.org/mdg/goal7.shtml (Accessed 18 April, 2010). 
62. World Health Organization. Progress on health-related Millennium Development Goals.(MDGs). Available from URL: http://www.who.int/mediacentre/ factsheets/fs290/en/index.html (Accessed 18 April, 2010).

63. Mintz ED, Guerrant RL. A lion in our village - the unconscionable tragedy of cholera in Africa. N Engl J Med. 2009;360:1060-3.

64. Aregawi M, Cibulskis R, Otten M, Williams R, Dye C. on behalf of WHO Global Malaria Programme. World malaria report 2008. Geneva: World Health Organization; 2008. Available from URL: http://malaria.who.int/ wmr2008/malaria2008.pdf (Accessed 17 March, 2010).

65. Global tuberculosis control: key findings from the December WHO report, WER. 2010;85: 69-80. Available from URL: http://www.who.int/wer/2010/ wer8509.pdf http://www.who.int/wer/en/ (Accessed 17 March, 2010).

66. World Health Organization. Multidrug and extensively drug-resistant TB (M/ XDR-TB): 2010 Global report on surveillance and response. Geneva: World Health Organization; 2010. Available from URL: http://whqlibdoc.who.int/ publications/2010/9789241599191_eng.pdf (Accessed 17 March, 2010).

67. World Health Organization. Tuberculosis: Fact sheet 104. Available from URL: http://www.who.int/mediacentre/factsheets/fs104/en/print.html (Accessed 17 April, 2010).

68. World Health Organization. AIDS epidemic update: 2009. Available from URL: http://www.who.int/hiv/pub/epidemiology/epidemic/en/index.html (Accessed 17 March, 2010).

69. World Health Organization. Global plan to combat neglected tropical diseases, 2008-2015. Geneva, Switzerland: World Health Organization; 2007. Available from URL: http://whqlibdoc.who.int/hq/2007/WHO_CDS_NTD_2007.3_ eng.pdf (Accessed 17 March, 2010).

70. Burki T. East African countries struggle with visceral leishmaniasis. Lancet. 2009;374:371-2.

71. Hotez PJ, Molyneux DH, Fenwick A, Kumaresan J, Ehrlich Sachs S, Sachs J, et al. Control of neglected tropical diseases. N Engl. J Med. 2007;357:1018-27.

72. World Health Organization. Global strategy for prevention and control of sexually transmitted infections: 2006-2015. Geneva: World Health Organization; 2007. Available from URL: http://whqlibdoc.who.int/publications/2007/ 9789241563475_eng.pdf (Accessed 17 April, 2010).

73. Flahault A, Zylberman P. Influenza pandemics past and future. Public Health Reviews 2010;32:319-340.

74. File TM, Marrie TJ. Burden of community-acquired pneumonia in North American adults. Postgrad Med. 2010;122(2):130-41.

75. Lo Bue P, Sizemore C, Castro KG. Plan to control excessively drug-resistant tuberculosis: Recommendations of the Federal Tuberculosis Task Force. MMWR Morb Mortal Wkly Rep. 2009;58:(RR3)1-43.

76. Werner G, Bronzwaer S. Ensuring prudent use of antimicrobials in human medicine in the European Union, 2005. Euro Surveill. 2007;12:677. 
77. Editorial Team. Ensuring prudent use of antimicrobials in human medicine: forceful action needed in Europe. Eurosurveill. 2006;11: Issue 2, article 3. Available from URL: http://www.eurosurveillance.org/ViewArticle. aspx?ArticleId=2873 (Accessed 3 June, 2010).

78. Klein E, Smith DL, Laxminarayan R. Hospitalizations and deaths caused by methicillin-resistant Staphylococcus aureus, United States, 1999-2005. Emerg Inf Dis, 2007;13:1840-6.

79. Water Quality and Health Council. Hospital-acquired infections a menacing trend in health care settings: guidance for hospital personnel and patients offered. Available from URL: http://www.waterandhealth.org/newsletter/ new/winter_2003/hospital.html (Accessed 17 March, 2010).

80. Wenzel RP, Edmond MB. Impact of hospital-acquired bloodstream infections. Emerg Infect Dis. 2001;7:174-7.

81. Rosenthal VD, Maki DG, Salomao R, Moreno CA, Mehta Y, Hignera F, et al. The International Nosocomial Infection Control Consortium. Deviceassociated nosocomial infections in 55 intensive care units of 8 developing countries. Ann Intern Med. 2006;17;145:582-91.

82. Rosenthal VD, Maki DG, Graves N. The International Nosocomial Infection Control Consortium (INICC): goals and objectives, description of surveillance methods, and operational activities. Am J Infect Control. 2008;36:e1-12.

83. World Health Organization. Conclusions and recommendations of the Advisory Committee on Poliomyelitis Eradication, November 2009, WER Wkly Epidemiol Rec. 2010; 85:1-12.

84. World Bank. World development report 2010: development and climate change. Washington (DC): The World Bank; 2009. Available from URL: http://go. worldbank.org/BKLQ9DSDU0 (Accessed 14 March, 2010).

85. World Bank. 'Climate Smart' world within reach. Press release: 2010/068/DEC. Available from URL: http://www.worldbank.org/CEYPuLI100 (Accessed 17 April, 2010).

86. Menne B, Apfel F, Kovats S, Racioppi F. Protecting health in Europe from climate change. Geneva: World Health Organization; 2008. Available from URL: http://www.euro.who.int/Document/E91865.pdf (Accessed 17 April, 2010).

87. Kumaresan J, Sathiakumar N. Climate change and its potential impact on health: a call for integrated action. Bull World Health Organ. 2010;88:163.

88. Byass P. Climate change and population health in Africa: where are the scientists? Global Health Action. 2009; Nov. 11:2. Available from URL: http://www. ncbinlm.nih.gov/fms/articles/pmc2799228/?Tool=pubmed (Accessed 17 April, 2010).

89. Slenning BD. Global climate change and implications for disease emergence. Vet Pathol. 2010;47:28-33.

90. Hill AVS. Aspects of genetic susceptibility to human infectious disease. Ann Rev Genet. 2006;40:469-86.

91. Frodsham AJ, Hill AV. Genetics of infectious diseases. Hum Mol Genet. 2004; 13:R187-94. 
92. Chen WH, Kozlovsky BF, Effros RB, Grubeck-Loebenstein B, Edelman R, Sztein B. Vaccination in the elderly: an immunological perspective, Trends Immunol. 2009;7:351-9.

93. Rose G. Sick individuals and sick populations. Int J Epidemiol. 1985;14:32-38.

94. World Health Organization. Measles: key facts. Available from URL: http://www.who.int/mediacentre/factsheets/fs286/en/index.html (Accessed 17 March, 2010).

95. Kremer JR, Muller CP. Measles in Europe: there is room for improvement. Lancet. 2009;373:356-8.

96. Muscat M, Bang H, Wohlfahrt J, Glismann G, Mølbak K. Measles in Europe: an epidemiologic assessment. Lancet. 2009;373:383-9.

97. Centers for Disease Control. Global measles mortality, 2000 - 2008. MMWR Morb Mort Wkly Rep. 2009; 58;1321-6. Available from URL: http://www. cdc.gov/mmwr/preview/mmwrhtml/mm5847a2.htm (Accessed 18 April, 2010).

98. Duncan B., How the media reported the first days of the pandemic (H1N1) 2009: results of EU-wide media analysis. Euro Surveill. 2009; 14(30): pi=19286. Available from URL: http://www.eurosurveillance.org/View Article.aspx?ArticleId=19286 (Accessed 14 March, 2010).

99. World Health Organization. Outbreak communication: best practices for communicating with the public during an outbreak, Report of the WHO expert consultation on outbreak communications held in Singapore, 21 -23 September 2004. Geneva: World Health Organization; 2005. Available from URL: http://www.who.int/csr/resources/publications/WHO_ CDS_2005_32web.pdf (Accessed 17 March, 2010).

100. Centers for Disease Control. Updated CDC estimates of 2009 H1N1 influenza cases, hospitalizations and deaths in the United States, April 2009 - February 13, 2010. Available from URL: http://www.cdc.gov/h1n1flu/estimates_ 2009_h1n1.htm (Accessed 17 March, 2010).

101. Centers for Disease Control. Recommended Immunization Schedules for Persons Aged 0 Through 18 Years - United States, 2010. MMWR Morb Mort Wkly Rep. 2010;58(51\&52):1-4.

102. National Health Service (NHS) Vaccinations: your NHS guide to vaccinations for you and your family. Available from URL: http://www.immunisation. nhs.uk/Immunisation_Schedule (Accessed 14 May, 2010).

103. EUVAC.NET. National childhood vaccination schedules. A surveillance community network for vaccine preventable diseases. Posted 27 Feb 2009. Available from URL: http://www.euvac.net/graphics/euvac/vaccination/ vaccination.html (Accessed 15 May, 2010).

104. Jones KE, Patel NG, Levy MA, Storeygard A, Balk D, Gittleman JL, et al. Global trends in emerging infectious diseases. Nature. 2008;451:990-3.

105. World Health Organization. Meeting of the International Task Force for Disease Eradication, June 2009: Measles. WER Wkly Epidemiol Rec. 2009; 84: 453-68. 
106. Kaml M, Weiskirchner I, Keller M, Luft T, Hoster E, Hasford J, et al. Booster vaccination in the elderly: their success depends on vaccine type applied earlier in life as well as well as on pre-vaccination antibody titers. Vaccine. 2006;24:6808-11.

107. WHO, UNICEF, World Bank. State of the world's vaccines and immunization, third edition: Geneva: World Health Organization; 2009. Available from URL: http://whqlibdoc.who.int/publications/2009/9789241563864_eng.pdf (Accessed 16 March, 2010).

108. Centers for Disease Control. Licensure of 13-valentpneumococcal conjugate vaccine (PCV13) and recommendations for use among children - Advisory Committee on Immunization Practices (ACIP) 2010. MMWR Morb Mort Wkly Rep. 2010:59;259-61.

109. Kumar R, Burns EA. Age-related decline in immunity: implications for vaccine responsiveness. Expert Rev Vaccines. 2008;7:467-79.

110. Centers for Disease Control. Recommended Immunization Schedules for Persons Aged 0 Through 18 Years - United States, 2009. MMWR Morb Mort Wkly Rep. 2010;58 (51\&52):1-4.

111. Smith JC, Snider DE, Pickering LK. Immunization policy development in the United States: the role of the Advisory Committee on Immunization Practices. Ann Intern Med. 2009; 150:45-49.

112. World Health Organization. Ebola Haemorrhagic fever. Fact sheet. Available from URL: http://www.who.int/mediacentre/factsheets/fs103/en/ (Accessed 17 April, 2010).

113. Centers for Disease Control and Prevention. Special Pathogens Branch. Known cases and outbreaks of Marburg Hemorrhagic Fever, in chronological order. July 31, 2009. Available from URL: http://www.cdc.gov/ncidod/dvrd/ spb/pdf/marburghftable.pdf (Accessed 17 April, 2010).

114. The National Advisory Committee on SARS and Public Health. Learning from SARS: renewal of public health in Canada. Ottawa, Canada: Government of Canada; 2003. Available from URL: http://www.phac-aspc.gc.ca/ publicat/sars-sras/naylor/exec-eng.php (Accessed 17 April, 2010).

115. Boesen A, Sundar K, Coico R. Lassa fever virus peptides predicted by computational analysis induce epitope-specific cytotoxic-T-lymphocite responses in HLA-A2.1 transgenic mice. Clin Diagn Lab Immunol. 2005; 12:1223-30.

116. MacPherson DW, Gushulak BD, Baine WB, Bala S, Gubbins PO, Holton P, et al. Population mobility, globalization and antimicrobial drug resistance. Emerg Infect Dis. 2009;15:1727-32.

117. Fischer Walker CL, Fontaine O, Young MW, Black RE. Zinc and low osmolarity oral rehydration salts for diarrhoea: a renewed call to action. Bull World Health Organ. 2009;87:780-6.

118. Govella NJ, Okumu FO, Killeen GF. Insecticide-treated nets can reduce malaria transmission by mosquitos which feed outdoors. Am J Trop Med. 2010;82:415-9. 
119. International Task Force for Disease Eradication (ITFDE). Summary of the twelfth meeting of the IFTDE, May 6, 2008. Available from URL: http:// www.cartercenter.org/resources/pdfs/news/health_publications/itfde/ ITFDEsum0508.pdf (Accessed 17 March, 2010).

120. Uthman OA, Popoola TA, Uthman MM, Aremu O. Economic evaluations of adult male circumcision for prevention of heterosexual acquisition of HIV in men in Sub-Saharan Africa: a systematic review. PLoS One. 2010 March 10;5:e9628.

121. Binagwaho A. Pigurri E. Muita J, Bertozzi S. Male circumcision at different ages in Rwanda: a cost-effectiveness study. PLoS Med. 2010;7(1):e1000211.

122. United Nations UNAIDS. AIDS epidemic update2009. New York: United Nations; 2009. Available from URL: http://unaids.org/en/KnowledgeCentre/ HIVData/EpiUpdate/EpiUpdArchive/2009/default.asp (Accessed 14 March, 2010).

123. World Health Organization. Millennium Development Goal 6: combat HIV/ AIDS, malaria and other diseases. Geneva: World Health Organization; 2009 Available from URL: http://www.who.int/hiv/topics/mdg/info/en/ print.html (Accessed 14 March, 2010).

124. Bill and Melinda Gates Foundation. Bill and Melinda Gates pledge $\$ 10$ billion in call for decade of vaccines. Press release, January 29, 2010 Available from URL: http://www.gatesfoundation.org/press-releases/Pages/decade-ofvaccines-wec-announcement-100129.aspx (Accessed 14 March, 2010). 